\title{
A prospective study of clinicoepidemiology, metabolic and hormonal profile of women with hirsutism in Konaseema region of Andhra Pradesh
}

\author{
M. Smitha* \\ Department of Obstetrics and Gynaecology, Konaseema Institute of Medical Science, Amalapuram, Andhra Pradesh, \\ India
}

Received: 12 August 2021

Accepted: 04 September 2021

\section{*Correspondence:}

Dr. M. Smitha,

E-mail: drmsmitha@gmail.com

Copyright: $\odot$ the author(s), publisher and licensee Medip Academy. This is an open-access article distributed under the terms of the Creative Commons Attribution Non-Commercial License, which permits unrestricted non-commercial use, distribution, and reproduction in any medium, provided the original work is properly cited.

\section{ABSTRACT}

Background: Hirsutism is defined as presence of excess coarse hairs appear in male pattern in women. There is various aetiology of hirsutism like Idiopathic hirsutism, PCOS, androgen secreting ovarian tumours, menopause, $\mathrm{CAH}$, Cushing's syndrome, drugs which increases testosterone level, insulin resistance and tumour secreting androgen. We have designed present study with an aim to study the clinicoepidemiology, metabolic and hormonal profile of women with hirsutism in Konaseema region of Andhra Pradesh.

Methods: All patients with hirsutism attending gynaecology outpatient department were selected for study based on inclusion and exclusion criteria. After that patient were examined clinically, BMI was calculated for each patient. Patients were clinically evaluated for signs of excess androgen secretion, Cushing syndrome, metabolic syndrome and hyperprolactinemia. Modified Ferriman-Gallwey scoring system was used for evaluating and quantifying hirsutism.

Results: The mean Fasting plasma insulin12.42 \pm 2.41 (mIU/dl), the mean of HOMA-IR was $3.14 \pm 1.18$. The mean value of dehydroepiandrosteronesulphate (DHEAS) $355.78 \pm 15.41 \mathrm{mcg} / \mathrm{dl}$. There was statistically significant reduction in modified Ferriman-Gallwey scoring in before and after treatment (12.38 \pm 1.55 vs. $9.62 \pm 1.6)$, the p value was 0.00001 . The number of patients with menstrual irregularities were reduced from $63.3 \%$ to $20 \%$ after treatment and this difference is statistically significant $(\mathrm{p}=0.04)$.

Conclusions: Hirsutism is associated with insulin resistance and DHEAS concentration was high. Modified Ferriman-Gallwey score was significantly reduced and there was significant weight loss and improvement in menstrual irregularities after treatment.

Keywords: Clinicoepidemiology, Metabolic, Hormonal profile of women, Hirsutism

\section{INTRODUCTION}

Hirsutism is a common, complex and difficult medical condition, associated with psychosocial disturbance to patients as well as attendant. Hirsutism is defined as presence of excess coarse hairs appear in male pattern in women. ${ }^{1,2}$ Affected areas include the upper lip, cheeks, chin, back, thighs, upper part of the arms, and central parts of the chest and lower parts of the abdomen. ${ }^{3}$ The prevalence of hirsutism is 10 to $15 \%$ in India. ${ }^{4}$ In women it may be due to increased secretion of androgen from ovaries, adrenal medulla or because of increased sensitivity of hair follicle to androgen. Hirsutism is not a disease by itself but it indicates an abnormality in androgen metabolism but it can be androgen dependent and androgen independent. ${ }^{5}$ There is various aetiology of hirsutism like Idiopathic hirsutism, PCOS, androgen secreting ovarian tumours, menopause, $\mathrm{CAH}$, Cushing's 
syndrome, drugs which increases testosterone level, insulin resistance and tumour secreting androgen. ${ }^{6}$

After going through literature search, we have found that there are some studies are available regarding clinicepidemiology, metabolic and hormonal profile of women with hirsutism. Sharma et al has concluded from his study that IH as the commonest cause of hirsutism in our study population. Face, chest, and lower abdomen have a higher impact on the hirsutism score while upper back, abdomen, and lower back are rarely involved. ${ }^{7}$ Dhanotia et al has concluded from his study that Idiopathic hirsutism was the most common cause of hirsutism in our study which was followed by polycystic ovarian syndrome. However, before categorizing the patient as a case of $\mathrm{IH}$, it is necessary to completely investigate the patient for all possible causes to manage the patient effectively. ${ }^{8}$ Ikram et al has concluded from his study that hirsutism of polycystic ovary syndrome or idiopathic origin is not uncommon in Indian women. ${ }^{9}$

Hirsutism of adrenal or thyroid origin remains uncommon. But there is paucity of literature regarding clinicoepidemiology, metabolic and hormonal profile of women with hirsutism. So, we have designed present study with an aim to study the clinicoepidemiology, metabolic and hormonal profile of women with hirsutism in Konaseema region of Andhra Pradesh.
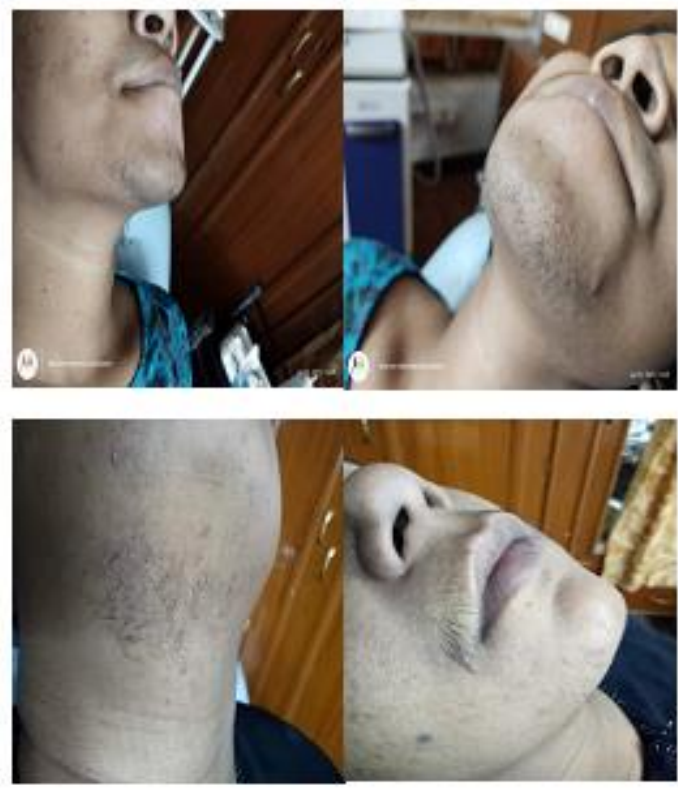

Figure 1: Hirsutism in facial region.

\section{METHODS}

\section{Study type, location and duration}

This is a prospective descriptive study, conducted in the department of obstetrics and gynaecology Konaseema institute of medical science, Amalapuram, Andhra Pradesh India from May 2018 to June 2021.

\section{Selection of patients}

All patients with hirsutism attending gynaecology outpatient department were selected for study based on inclusion and exclusion criteria. A written informed consent was obtained from all patients before enrolling them for study.

\section{Inclusion criteria}

Inclusion criteria for current study were; age more than 14 years and below 60 years and modified FerrimanGallwey scoring $>8$.

\section{Exclusion criteria}

Exclusion criteria for current study were; postmenopausal women, pregnancy and hypertrichosis.

\section{Sample size}

Sample size was calculated to be 60 by considering prevalence $15 \%$ from previous study and using formulae;

$\mathrm{n}=\mathrm{Z}^{2} \mathrm{P}(1-\mathrm{P}) / \mathrm{d}^{2}$

Where $\mathrm{n}$ is the sample size, $\mathrm{Z}$ is the statistic corresponding to level of confidence, $\mathrm{P}$ is expected prevalence. ${ }^{10}$

\section{Procedure}

During our study period of three years, we have enrolled 60 patients with hirsutism were included as per selection criteria. After that detail history of patients regarding age of onset duration of onset of hirsutism, menstrual irregularities, infertility, weight gain and medication was taken was taken. After that patient was examined clinically, BMI was calculated for each patient. Patients were clinically evaluated for signs of excess androgen secretion, Cushing syndrome, metabolic syndrome and hyperprolactinemia. Modified Ferriman-Gallwey scoring system was used for evaluating and quantifying hirsutism. ${ }^{11}$ Ultrasonography of pelvis was done for detection of polycystic ovarian disease, any abnormality of uterus or adnexal mass. USG of abdomen was done to evaluated congenital adrenal hyperplasia or ovarian mass. To diagnose malignant ovarian tumours and confirmation of congenital adrenal hyperplasia CT abdomen was done. $3 \mathrm{ml}$ of blood sample will be drawn from all the subjects following an overnight fast of 8 to 10 hours. Various parameter like, fasting plasma glucose, HDL-C, LDL-C, TG (triglycerides), Total cholesterol, fasting plasma insulin, and HOMA-IR were measured. Hexokinase method was used for estimation of plasma glucose. For total cholesterol, we used Liebermann Burchard reaction colorimetric method; triglyceride was estimated by method of Neri and Fringe. HDL concentration was estimated by precipitation method. LDL concentration was calculated by WHO formula, LDL-cholesterol = total 
cholesterol-TG/5-HDL (mg/dl). ${ }^{12}$ Plasma insulin was determined by using enzyme linked immunosorbent assay. HOMA-IR was calculated by using this formula (FPI X FPG)/22.5. For estimation of other parameters COBASE 411 immunochemistry analyser was used. Free testosterone and dehydroepiandrosterone sulphate levels from venous blood were measured in all individuals using COBASE 411 immunochemistry analyser was used. All patients were treated as per underlying pathology and for that standard treatment protocol was followed. Local measures were taken for patients with mild hirsutism.

\section{Statistical analysis}

Data were recorded in excel sheet and statistical Analysis was done with software SPSS-14 version. Qualitative data were calculated as percentage and proportions. Quantitative data were expressed as mean \pm SD. Chi square test and unpaired t test were used form analysis of data and $p$ value less than 0.05 was considered statistically significant.

\section{RESULTS}

In present study we have enrolled 60 patients with hirsutism as per selection criteria for evaluation of clinicoepidemiology, metabolic and hormonal profile. As per (Table 1) mean age of patients were $32.12 \pm 6.12$ years. We have observed that number of patients below 20 years were $8(13.3 \%)$, between 21 to 40 years were 44 $(73.3 \%)$ and between 41 to 60 years were $8(13.3 \%)$. Regarding marital status $42(70 \%)$ were married and 18 $(30 \%)$ were unmarried. Infertility was present in $20 \%$ patients and absent in $80 \%$ patients. Family history was present in $56.67 \%$ patients and in $43.37 \%$ patients have no family history of hirsutism. Menstrual irregularities were present in $63.3 \%$ patients and in $36.6 \%$ patients have no menstrual irregularities. Weight gain was present in $76.6 \%$ patients and in $23.34 \%$ patients have no weight gain. In most of the patients $(60 \%)$ aetiology was idiopathic, $36.6 \%$ patients were diagnosed to be PCOS, malignancy was diagnosed in one patient and in one patient it was drug induced. The mean value of modified Ferriman-Gallwey scoring was $12.62 \pm 1.85$.

Regarding metabolic profile of patients, the mean of BMI was $26.47 \pm 1.89 \mathrm{~kg} / \mathrm{m} 2$; mean of fasting plasma glucose was $88.25 \pm 8.28 \mathrm{mg} / \mathrm{dl}$. The mean of serum triglyceride was $185.72 \pm 14.26 \mathrm{mg} / \mathrm{dl}$. The mean of serum LDL was $135.23 \pm 21.41 \mathrm{mg} / \mathrm{dl}$. The mean of serum HDL was $36.41 \pm 2.98 \mathrm{mg} / \mathrm{dl}$. The mean of total cholesterol was $174.87 \pm 32.64 \mathrm{mg} / \mathrm{dl}$. Regarding hormonal profile of patients with hirsutism, the mean Fasting plasma insulin $12.42 \pm 2.41(\mathrm{mIU} / \mathrm{dl})$, the mean of HOMA-IR was $3.14 \pm 1.18$. The mean value of dehydroepiandrosteronesulphate (DHEAS) 355.78 $\pm 15.41 \mathrm{mcg} / \mathrm{dl}$. Regarding outcome of treatment of patients with hirsutism, there was statistically significant reduction in modified Ferriman-Gallwey scoring in before and after treatment $(12.38 \pm 1.55$ vs. $9.62 \pm 1.6)$, the $p$ value was 0.00001 .there was statistically significant reduction in weight before and after treatment $(86.21 \pm 22.78$ vs. $76.62 \pm 19.18)$, the $p$ value was 0.02 . The number of patients with menstrual irregularities were reduced from $63.3 \%$ to $20 \%$ after treatment and this difference is statistically significant $(\mathrm{p}=0.04)$.

Table 1: Clinicodemographic profile of patients with hirsutism.

\begin{tabular}{|c|c|c|c|}
\hline \multicolumn{2}{|l|}{ Variable } & $\mathbf{N}$ & $\%$ \\
\hline \multirow{3}{*}{$\begin{array}{l}\text { Age }(32.12 \pm 6.12 \\
\text { years })\end{array}$} & Less than 20 & 8 & 13.3 \\
\hline & 21 to 40 & 44 & 73.3 \\
\hline & 41 to 60 & 8 & 13.3 \\
\hline \multirow{2}{*}{ Marital status } & Married & 42 & 70 \\
\hline & Unmarried & 18 & 30 \\
\hline \multirow{2}{*}{ Infertility } & Present & 12 & 20 \\
\hline & Absent & 48 & 80 \\
\hline \multirow{2}{*}{ Family history } & Present & 34 & 56.67 \\
\hline & Absent & 24 & 43.34 \\
\hline \multirow{2}{*}{$\begin{array}{l}\text { Menstrual } \\
\text { irregularity }\end{array}$} & Present & 38 & 63.3 \\
\hline & Absent & 22 & 36.6 \\
\hline \multirow{2}{*}{ Weight gain } & Present & 46 & 76.6 \\
\hline & Absent & 14 & 23.34 \\
\hline \multirow{4}{*}{ Aetiology } & Idiopathic & 36 & 60 \\
\hline & PCOS & 22 & 36.6 \\
\hline & Malignancy & 1 & 1.67 \\
\hline & Drugs & 1 & 1.67 \\
\hline \multicolumn{2}{|c|}{$\begin{array}{l}\text { Modified Ferriman-Gallwey } \\
\text { scoring }\end{array}$} & \multicolumn{2}{|c|}{$12.62 \pm 1.85$} \\
\hline
\end{tabular}

Table 2: Metabolic profile of patients with hirsutism.

\begin{tabular}{|ll|}
\hline Variable & Mean \pm SD \\
\hline BMI $(\mathbf{k g} / \mathbf{m} 2)$ & $26.47 \pm 1.89$ \\
\hline FPG $(\mathbf{m g} / \mathbf{d l})$ & $88.25 \pm 8.28$ \\
\hline TG $(\mathbf{m g} / \mathbf{d l})$ & $185.72 \pm 14.26$ \\
\hline LDL $(\mathbf{m g} / \mathbf{d l})$ & $135.23 \pm 21.41$ \\
\hline HDL $(\mathbf{m g} / \mathbf{d l})$ & $36.41 \pm 2.98$ \\
\hline T Chol $(\mathbf{m g} / \mathbf{d l})$ & $174.87 \pm 32.64$ \\
\hline
\end{tabular}

Table 3: Hormonal profile of patients with hirsutism.

\begin{tabular}{|ll|}
\hline Variable & Mean \pm SD \\
\hline Fasting plasma insulin(mIU/dl) & $12.42 \pm 2.41$ \\
\hline HOMA -IR & $3.14 \pm 1.18$ \\
\hline $\begin{array}{l}\text { Dehydroepiandrosteronesulphate } \\
\text { (DHEAS) (mcg/dl) }\end{array}$ & $355.78 \pm 15.41$ \\
\hline
\end{tabular}

\section{DISCUSSION}

During study period of three years, we enrolled 60 patients as per selection criteria. The mean age of patients was $32.12 \pm 6.12$ years and most of the participants were between 21 to 40 years. Tehrani et al from Kashmir India reported that the mean $\pm \mathrm{SD}$ of age of study population 
was 29.2 \pm 8.7 years and Escobar-Morreale et al has reported that hirsutism is common in women in reproductive age group and decreases after 40 years of age these two studies support our study. ${ }^{13,14}$ In our study most of the patients were married, infertility was present in $20 \%$ patients and $56.6 \%$ patients have family history of hirsutism. Chhabra et al has reported that family history was present in $42.5 \%$ patient and most of the patients were unmarried which partially support our study and marital status of patients were depends upon sociocultural pattern of regional and local population in that way our marital percentage is high. ${ }^{15}$ Roth et al has reported that infertility with hirsutism is common with PCOS and idiopathic hirsutism is less associated with infertility which support our study. ${ }^{16}$ In most of the patients $(60 \%)$ aetiology was idiopathic, $36.6 \%$ patients were diagnosed to be PCOS, malignancy was diagnosed in one patient and in one patient it was drug induced. Li et al and Mina et al has study corroborates with our study. ${ }^{17,18}$ The mean of BMI was $26.47 \pm 1.89 \mathrm{~kg} / \mathrm{m} 2$ this finding is not supported by Ruutiainen et al. ${ }^{19}$ The mean of fasting plasma glucose was $88.25 \pm 8.28 \mathrm{mg} / \mathrm{dl}$. The mean of serum triglyceride was $185.72 \pm 14.26 \mathrm{mg} / \mathrm{dl}$. The mean of serum LDL was $135.23 \pm 21.41 \mathrm{mg} / \mathrm{dl}$. The mean of serum HDL was $36.41 \pm 2.98 \mathrm{mg} / \mathrm{dl}$. The mean of total cholesterol was $174.87 \pm 32.64 \mathrm{mg} / \mathrm{dl}$, this finding is supported by the work of Couto et al. ${ }^{20}$

Table 4: Treatment outcome of patients with hirsutism.

\begin{tabular}{|llll|l|}
\hline Variable & Before treatment & After treatment & P value \\
\hline Modified Ferriman-Gallwey scoring & $12.38 \pm 1.55$ & $9.62 \pm 1.6$ & 0.00 \\
\hline Weight loss & & $86.21 \pm 22.78$ & $76.12 \pm 19.18$ & 0.02 \\
\hline \multirow{2}{*}{ Menstrual irregularities } & Present & 38 & 12 & 0.04 \\
\cline { 2 - 6 } & Absent & 22 & 48 & \\
\hline
\end{tabular}

The mean fasting plasma insulin12.42 \pm 2.41 (mIU/dl) which indicates it is a hyperinosaemia $s$ and, the mean of HOMA-IR was $3.14 \pm 1.18$ which indicates a state of insulin resistance. Kürsad et al has concluded that $\mathrm{IH}$ (idiopathic hirsutism) is associated with some degree of insulin resistance and an increased tendency for glucose intolerance notably in obese women with $\mathrm{IH}^{21}$ Talaei et al has concluded that Insulin resistance should be assessed in all hirsute women with PCOS regardless of their body mass index which support our study. ${ }^{22}$ Talaei et al has concluded that idiopathic hirsutiam is associated with hirsutism. ${ }^{23}$ Sachdeva et al has concluded that raised DHEAS $(>700 \mu \mathrm{g} / \mathrm{dl})$ always indicates an adrenal cause, benign or malignant but in present study the mean value of dehydroepiandrosterone sulphate (DHEAS) $355.78 \pm 15.41 \mathrm{mcg} / \mathrm{dl}$ so adrenal may not be cause of hirsutism in our study. ${ }^{24}$ Pasquali et al has concluded that the percentages of women with PCOS and hirsutism who had elevated DHEA-S were higher than women with PCOS and no hirsutism with even increased serum mean values as established in our study which support our study. ${ }^{25}$ Regarding outcome of treatment of patients with hirsutism modified Ferriman-Gallwey score was significantly reduced. There was significant weight loss and improvement in menstrual irregularities this is supported by the work of Kathryn et al. ${ }^{26}$

\section{CONCLUSION}

From present study we can conclude that hirsutism is common in women in reproductive age group and decreases after 40 years of age. It is associated with weight gain, menstrual irregularity and have family history. Idiopathic hirsutism is common and Modified Ferriman-Gallwey score was high. BMI of patients was high and associated with metabolic derangement.
Hirsutism is associated with insulin resistance and DHEAS concentration was high. Modified FerrimanGallwey score was significantly reduced and there was significant weight loss and improvement in menstrual irregularities after treatment.

Funding: No funding sources Conflict of interest: None declared

Ethical approval: The study was approved by the Institutional Ethics Committee

\section{REFERENCES}

1. Rittmaster RS. Hirsutism. Lancet. 1997;349(9046): 191-5.

2. Phillipov G. Hirsutism. Lancet. 1997;349(9052):650.

3. Braithwaite SS, Jabamoni R. Hirsutism. Arch Dermatol. 1983;119(4):279-84.

4. Sharma NL, Mahajan VK, Jindal R, Gupta M, Lath A. Hirsutism: clinico-investigative profile of 50 Indian patients. Indian J Dermatol. 2008;53(3):111-4.

5. Chhabra S, Gautam RK, Kulshreshtha B, Prasad A, Sharma N. Hirsutism: A Clinico-investigative Study. Int J Trichology. 2012;4(4):246-50.

6. Krysiak R, Kedzia A, Okopień B. Current opinions on the etiology and pathophysiology of hirsutism. Pol Merkur Lekarski. 2012;32(191):335-40.

7. Sharma D, Shanker V, Tegta G, Gupta M, Verma GK. Clinico-investigative Profile of Patients of Hirsutism in a Tertiary Level Institution. Int J Trichology. 2012; 4(2):69-74.

8. Dhanotia PG, Shah BJ, Dhamale SS. A study of clinical and investigational profile of hirsute women at a tertiary care center in Western India. Clin Dermatol Rev. 2020;4:123-7

9. Ikram KM, Pushpinder SC, Monika C, Karaninder SM, Vijay KS, Anuj S, et al. Clinico-investigative 
attributes of 122 patients with hirsutism: A 5-year retrospective study from India. Int $\mathbf{J}$ Women's Dermatol. 2021;7(3): 237-42.

10. Daniel WW. Biostatistics: A Foundation for analysis in the health sciences. 7th ed. New York: John Wiley \& Sons. 1999.

11. Ferriman D, Gallwey JD. Clinical assessment of body hair growth in women. J Clin Endocrinol Metab. 1961;21:1440-7.

12. Friedewald WT, Levy RI, Fredrickson DS. Estimation of the concentration of low-density lipoprotein cholesterol in plasma, without use of the preparative ultracentrifuge. Clin Chem. 1972;18(6):499-502.

13. Tehrani FR, Rashidi H, Azizi F. The prevalence of idiopathic hirsutism and polycystic ovary syndrome in the Tehran lipid and glucose study. Reprod Biol Endocrinol. 2011;9:144.

14. Escobar-Morreale HF, Carmina E, Dewailly D, Gambineri A, Kelestimur F, Moghetti P, et al. Epidemiology, diagnosis and management of hirsutism: a consensus statement by the Androgen Excess and Polycystic Ovary Syndrome Society. Hum Reprod Update. 2012;18(2):146-70.

15. Chhabra S, Gautam RK, Kulshreshtha B, Prasad A, Sharma N. Hirsutism: A Clinico-investigative Study. Int J Trichology. 2012;4(4):246-50.

16. Roth LW, Huang H, Legro RS, Diamond MP, Coutifaris C, Carson SA, et al. Altering hirsutism through ovulation induction in women with polycystic ovary syndrome. Obstet Gynecol. 2012;119(6):11516.

17. Li R, Qiao J, Yang D, Li S, Lu S, Wu X, Wei Z. Epidemiology of hirsutism among women of reproductive age in the community: a simplified scoring system. Eur J Obstet Gynecol Reprod Biol. 2012;163(2):165-9.

18. Mina A, Aida F, Ali S, Fatemeh M. Prevalence of idiopathic hirsutism: A systematic review and metaanalysis. J Cosmetic Dermatol. 2021;5:85-9.
19. Ruutiainen K, Erkkola R, Grönroos MA, Irjala K. Influence of body mass index and age on the grade of hair growth in hirsute women of reproductive ages. Fertil Steril. 1988;50(2):260-5.

20. Couto Alves A, Valcarcel B, Mäkinen VP, MorinPapunen L, Sebert S, Kangas AJ, et al. Metabolic profiling of polycystic ovary syndrome reveals interactions with abdominal obesity. Int $\mathrm{J}$ Obes (Lond). 2017;41(9):1331-1340.

21. Glueck CJ, Phillips H, Cameron D, Sieve-Smith L, Wang P. Continuing metformin throughout pregnancy in women with polycystic ovary syndrome appears to safely reduce first-trimester spontaneous abortion: a pilot study. Fertility Sterility. 2001;75(1):46-52.

22. Cebeci F, Onsun N, Mert M. Insulin resistance in women with hirsutism. Arch Med Sci. 2012;8(2):3426.

23. Talaei A, Adgi Z, MohamadiKelishadi M. Idiopathic hirsutism and insulin resistance. Int $\mathbf{J}$ Endocrinol. 2013;2013:593197.

24. Sachdeva S. Hirsutism: evaluation and treatment. Indian J Dermatol. 2010;55(1):3-7.

25. Pasquali R, Zanotti L, Fanelli F, Mezzullo M, Fazzini A, MorselliLabate AM, et al. Defining Hyperandrogenism in women with polycystic ovary syndrome: a challenging perspective. $J$ Clin Endocrinol Metab. 2016;101(5):2013-22.

26. Kathryn A. Martin, R. Jeffrey C, David AE, Lourdes I, Rogerio A. Evaluation and treatment of hirsutism in premenopausal women: an endocrine society clinical practice guideline. J Clin Endocrinol Metabol. 2008; 93(4):1105-20.

Cite this article as: $M$. Smitha. A prospective study of clinicoepidemiology, metabolic and hormonal profile of women with hirsutism in Konaseema region of Andhra Pradesh. Int J Reprod Contracept Obstet Gynecol 2021;10:3875-9. 